\title{
Risk assessment and aspirin use in Asian and Western populations
}

This article was published in the following Dove Press journal:

Vascular Health and Risk Management

12 October 2010

Number of times this article has been viewed

\author{
Runlin Gao' \\ Xiaoying $\mathrm{Li}^{2}$ \\ 'Department of Cardiology, \\ Cardiovascular Institute and Fuwai \\ Hospital, Chinese Academy of Medical \\ Sciences, Beijing; ${ }^{2}$ Department of \\ Geriatric Cardiology, Chinese PLA \\ General Hospital, Beijing, China
}

Objective: The aim of this review was to examine aspirin utilization, cardiovascular risk estimation, and clinical evidence for aspirin prophylaxis in Asian versus Western countries.

Methods: A literature search was performed using PubMed and the key terms "aspirin" and "Asia" or "Western".

Results: Despite the growing burden of cardiovascular disease (CVD), aspirin is underutilized in high-risk patients in both Asian and Western countries. A number of risk estimation scores are available; however, validation is needed in countries such as Japan, India, and in South Asia. Underutilization of aspirin in Asia may be linked to an overestimation of bleeding risks. It is possible that a higher prevalence of Helicobacter pylori infection and genetic differences may make Asians more susceptible to gastrointestinal bleeding. Very low aspirin doses and even the wider use of gastroprotective agents may be the optimal approach to high-risk patients in Asia.

Conclusions: Based on the current evidence, aspirin should be used for CVD prevention when the risk:benefit ratio is favorable. A number of trials are underway, including the Diabetic Atherosclerosis Prevention by Cilostazol and Japanese Primary Prevention Project, which will provide key data on the benefits of aspirin in Asian patients at risk of CVD, and may improve aspirin utilization and risk estimation.

Keywords: aspirin, cardiovascular risk estimation, Asia, Western

\section{Introduction}

Cardiovascular disease (CVD) is a major cause of death worldwide. It is estimated that $58.1 \%$ of all deaths in Eastern Europe and Central Asia are due to CVD; the corresponding values in South Asia and East Asia and the Pacific are 25.2\% and 30.6\%, respectively. In high-income countries (mainly North America and Europe), 38.5\% of all deaths are attributable to CVD. ${ }^{1}$ These percentages are likely to increase, given that the worldwide mortality rate from CVD (including stroke) is predicted to rise to 25 million per year by $2020 .^{2,3}$ The increase in CVD death rates will be most dramatic in low- to middle-income Asian countries, such as India and China. In China alone, the number of deaths from CVD is estimated to reach a staggering 13 million by 2020.4,5 It is thought that the epidemiologic transition that is taking place in these countries could account for such changes. This transition may also result in a shift toward an aging population, which could further add to the burden of CVD, particularly in developing countries. ${ }^{1}$

Although the increasing prevalence of CVD is clearly a burden for many countries, ${ }^{1,2}$ the economic implications of the disease are a particular problem for many low- to 
middle-income Asian countries. ${ }^{6}$ It is estimated that 84 billion dollars of economic production will be lost due to CVD in low- to middle-income countries; however, an additional $2 \%$ reduction in annual death rates from CVD could save around 8 million dollars and prevent 24 million premature deaths, ${ }^{7}$ intensifying the need for effective preventive strategies.

Aspirin is one of the most effective antiplatelet agents for long-term prevention of vascular disease in individuals determined as having a high risk of CVD. ${ }^{8}$ The aim of this review is to examine aspirin utilization, CVD risk estimation, guideline recommendations, and clinical evidence for aspirin prophylaxis in Asian and Western countries.

\section{Methods}

A literature search was performed using PubMed and the search terms "aspirin; acetylsalicylic acid" and "Asia" or "European" or "Western" with the limits 'clinical trial', 'meta-analysis', 'practice guideline' and 'review'. The additional search terms "cardiovascular", "epidemiology", "utilization", "safety”, “efficacy”, "risk factors", "risk scores”, "primary prevention", "secondary prevention", and "nonresponsiveness" were also applied. All retrieved publications were manually reviewed and the relevant ones were organized according to the subheadings used in this review.

\section{Aspirin use in Asian and Western countries}

Despite consistent recommendations from international guidelines, ${ }^{9-15}$ aspirin is underutilized in many high-risk patients in both Western and Asian populations. ${ }^{16-19}$ In a survey of 7363 physicians from Europe, Latin America, and Asia, aspirin was recommended by most physicians (>85\%) for patients following myocardial infarction (MI). ${ }^{20,21}$ However, compliance was suboptimal; $45 \%$ of patients in Asia and 29\% of patients in Europe were estimated to be noncompliant according to the treating physician. The main reasons for underutilization of aspirin were poor patient compliance and poor patient follow-up..$^{20,21} \mathrm{~A}$ recent study of the Chinese Registry of Acute Coronary Events (CRACE) reported that only $34 \%$ of male patients and $39 \%$ of female patients with diagnosed acute coronary syndrome (ACS) used aspirin at study enrolment. ${ }^{22}$ Similarly, a study of Japanese patients in the Reduction of Atherothrombosis for Continued Health (REACH) registry revealed that aspirin use among Japanese patients with atherothrombotic disease was less common (54.7\%) than the global REACH average (67.4\%). ${ }^{23}$ Overall, these findings indicate that underutilization is an issue in both Asian and Western populations.

\section{CVD risk estimation in Asian and Western countries}

Two of the key issues to be addressed by physicians are the risk:benefit threshold at which prophylactic agents should be used, and which risk factors should be used to determine such thresholds. Gaziano et $\mathrm{al}^{24}$ suggest that risk factors can be divided into those that are predictive, those that are treatment targets, and those that fall into both categories (Figure 1). Many of these risk factors are correlated, making it possible to determine a patient's total CVD risk based on a few key risk factors. ${ }^{24}$ Nonlaboratory risk factors such as age, smoking status, and body mass index (BMI) have been found to be as predictive as laboratory methods such as cholesterol measures in both men and women, ${ }^{25}$ and other blood tests, such as high-sensitivity $\mathrm{C}$-reactive protein, hemoglobin $\mathrm{A}_{1 \mathrm{c}}$, fasting glucose, insulin, fibrinogen, adiponectin, triglycerides, and plasminogen activator inhibitor-1, which may help simplify risk prediction.

A number of risk estimation scores, which are based on factors such as age, smoking, BMI, and cholesterol, are available for determining total cardiovascular risk. Many of these scores are also based on the concept that risk factors occur in clusters, and scoring these clusters represents a logical way to determine which patients are eligible for treatment and to determine the threshold for intervention. ${ }^{26}$ There are a number of scores available; the key ones are summarized by Gaziano et al. ${ }^{24}$ These include the National Cholesterol Education Program-Adult Treatment Panel III (NCEP-ATP III) risk score, which predicts the 10-year CVD risk, the Systematic Coronary Risk Evaluation (SCORE) project, which calculates the 10-year risk of CVD death; the Prospective Cardiovascular Munster (PROCAM) study, which determines the 10 -year absolute risk of fatal MI, nonfatal MI or sudden cardiac death; and those produced by the New Zealand Guidelines Group that predict five-year total cardiovascular disease risk. ${ }^{27-30}$ The Reynolds Risk score, which incorporates high sensitivity C-reactive protein, predicts 10-year CVD risk in men and women. ${ }^{31,32}$ There are also a number of scores such as QRISK and ASSIGN, which are validated to specific populations such as the UK and Scotland. ${ }^{33}$

One of the most commonly used scores is the Framingham model, which can be used to predict coronary heart disease (CHD) risk (defined as MI, CHD death, angina, and coronary insufficiency) ${ }^{34}$ and CVD risk (defined as CHD plus stroke, congestive heart failure, and peripheral vascular disease). ${ }^{35}$ The Framingham model was originally developed in Western populations and has been validated in a Chinese population. ${ }^{36}$ However, there is also evidence to 


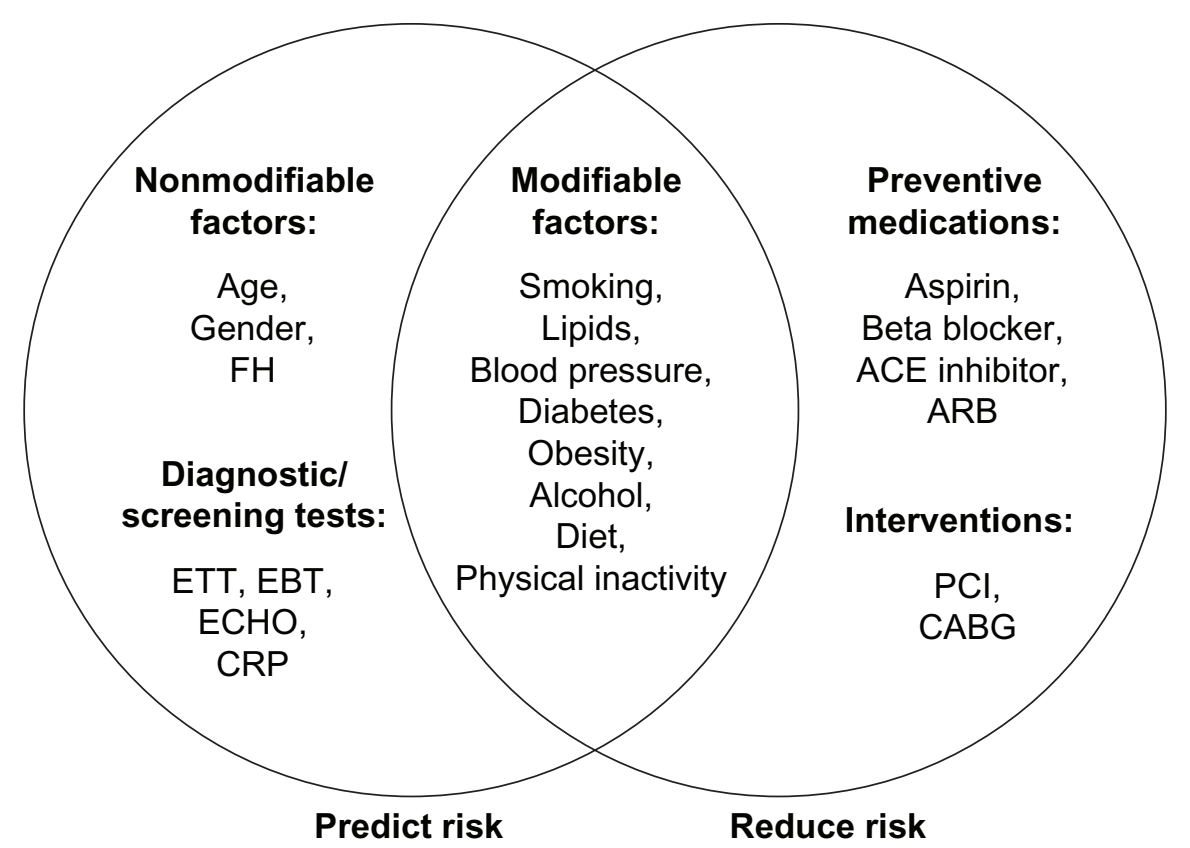

Figure I Risk factors can be divided into those that are predictive, those that are treatment targets, and those that fall into both categories. ${ }^{24}$ Copyright $\odot$ 2007, Elsevier. Reproduced with permission from Gaziano JM, Manson JE, Ridker PM. Primary and secondary prevention of coronary heart disease. In: Libby P, Bonow RO, Mann DL, et al, editors. Libby: Braunwald's Heart Disease:A Textbook of Cardiovascular Medicine. 8th ed. Philadelphia, PA: Saunders; 2007; I I 9 - I I 48.

Abbreviations: ACE, angiotensin-converting enzyme; ARB, angiotensin receptor blocker; CABG, coronary artery bypass graft; CRP, C-reactive protein; EBT, electron beam tomography; $\mathrm{ECHO}$, echocardiography; $\mathrm{ETT}$, exercise tolerance test; $\mathrm{FH}$, family history; $\mathrm{PCl}$, percutaneous coronary intervention.

suggest that the Framingham model overestimates CHD risk and underestimates CVD risk in China when compared with a prediction model specific to the Chinese population (Figure 2) ${ }^{37}$ This finding is based on a cohort of 9903 patients from the US-People's Republic of China (US-PRC) cohort, where the actual incidence of ischemic CVD and CHD was determined over an 11-year follow-up period. The Chinese prediction model accounts for the higher prevalence of stroke in China, ${ }^{37}$ which could be the main reason for the different results. However, the authors do not state whether the Framingham model was recalibrated to take into account the CVD definition (including stroke) that is described above.

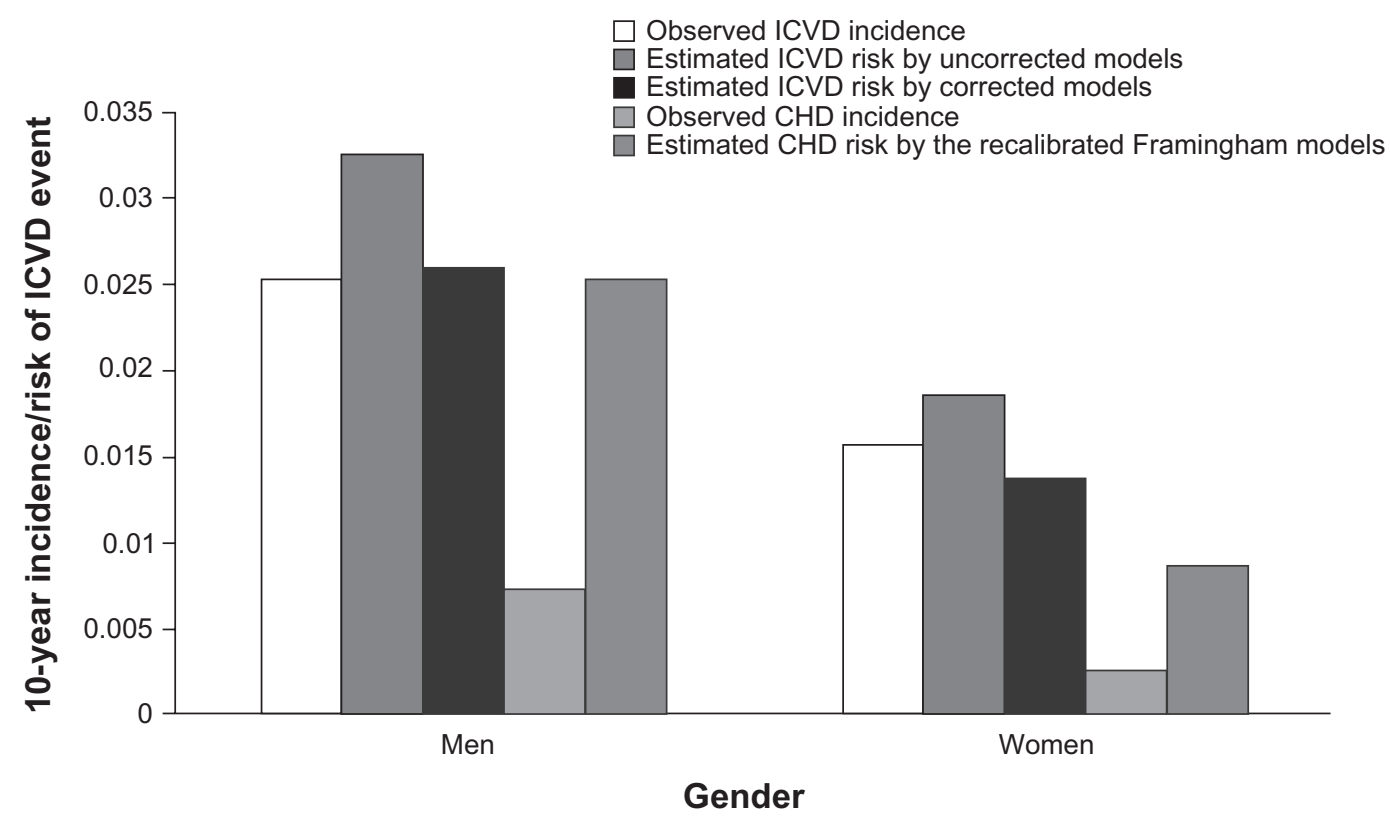

Figure 2 Comparison of Framingham model and Chinese prediction model on ischemic CVD and CHD incidence in a Chinese cohort. ${ }^{37}$ Copyright $(92006$. Reproduced with permission from Wu YF, Liu XQ, Li X, et al. Estimation of 10-year risk of fatal and non-fatal ischemic cardiovascular diseases in Chinese adults. Circulation. 2006; I I4(2I):22 I7-2225. Abbreviations: CHD, coronary heart disease; ICVD, ischemic cardiovascular disease. 
The main differences between the Framingham model and the Chinese prediction model relate to age (Framingham captures an older cohort), cholesterol (the Chinese prediction model only captures total cholesterol), BMI (only included in the Chinese prediction model), and diastolic blood pressure (only in the Framingham model).

A number of studies have also shown that cardiovascular risks differ between European and Asian countries. The International Collaborative Study of Cardiovascular Disease in Asia (InterASIA) survey found that risk levels were lower in China than in the US (Table 1). ${ }^{38}$ These authors used dyslipidemia, hypertension, diabetes, smoking, and weight to assess risk level; however, age was not used as part of the initial assessment. Comparison of Western and Asian data also reveals that different levels of risk are found within the two regions; based on data from a Japanese survey, a 50 -year-old male with no hypertension or diabetes in the US has a $3 \%$ risk of developing CVD in the subsequent five years, while a male with the same profile in Japan has a risk of only $0.8 \% .{ }^{39}$ The World Health Organization (WHO) determined the percentage of patients with a 10 -year CVD risk $\geq 30 \%$; they reported that $11.7 \%$ of the US population, $16.19 \%$ of the European population, and $11.44 \%$ of the Asia-Pacific population were in this category (data are pooled percentages), ${ }^{26}$ which indicates that risks were comparable between the US and Asia but were much higher in Europe.

In addition to validating risk estimation scores in Asian populations, there is also evidence to suggest that developing country-specific models or recalibrating and validating existing models such as the NCEP-ATP III, SCORE, or Framingham model could result in more accurate CVD risk estimates. Using a derivation cohort of 1.28 million and a validation cohort of 0.61 million patients from practices in the UK, cardiovascular risks were calculated using QRISK and Framingham, and were compared against actual events over a 10-year period. ${ }^{33}$ The Framingham model overpredicted cardiovascular risk at 10 years by $35 \%$ and QRISK

Table I Prevalence of major cardiovascular risk factors* in rural and urban China and the US ${ }^{\dagger}$

\begin{tabular}{llll}
\hline & \multicolumn{2}{l}{ China \% (SE) } & US \% (SE) \\
\cline { 2 - 3 } & Rural & Urban & \\
\hline$\geq$ I risk factor & $79.9(0.5)$ & $83.1(0.5)$ & $93.1(I .1)$ \\
$\geq 2$ risk factors & $44.0(0.7)$ & $53.6(0.7)$ & $73.0(1.8)$ \\
$\geq 3$ risk factors & $15.4(0.5)$ & $24.5(0.6)$ & $35.9(1.8)$ \\
\hline
\end{tabular}

Notes: *Risk factors were dyslipidemia, hypertension, diabetes, current smoking, and overweight. ${ }^{\dagger}$ Adapted from Gu et al. ${ }^{38}$

Abbreviation: SE, standard error. by $0.4 \%$, which indicates that QRISK may be better suited to the UK population. It is possible that a similar trend may be observed in different Asian countries.

Risk profiles may also differ between different Asian countries, which is another reason for country-specific rather than regional guidelines. In one case-control study involving 27,095 patients, the mean age for first MI was lower in South Asian countries compared with other countries, including other Asian countries (53 versus 58.8 years; $P<0.001$ ). ${ }^{40}$ South Asians were found to have more risk factors, such as lipid abnormalities and diabetes at a younger age ( $<60$ years) compared with the other countries. The INTERHEART study, which enrolled 12,190 patients, also showed that South Asians had lower high-density lipoprotein (HDL) cholesterol compared with the rest of Asia. ${ }^{41}$ South Asians have also been shown to have a higher incidence of fatal CHD at a younger age compared with Chinese or European subjects. ${ }^{42-44}$ These findings indicate that age thresholds, HDL cholesterol and CHD risk levels may be different in South Asia compared with the rest of Asia, and these need to be incorporated into risk estimation scores. Differences in diet may also be another factor worthy of consideration. Other studies have shown that insulin resistance may be higher in American Indians and triglyceride levels may be higher in Japanese Americans compared with other American populations, ${ }^{45}$ if such factors are not addressed in risk estimation scores then it is possible that total risk will not be properly addressed.

In order to encourage the wider use of risk estimation scores in different countries, the WHO has produced a series of pocket guidelines for Africa, the US, the Eastern Mediterranean, Europe, South-East Asia, and the Western Pacific, which take these different risk profiles into account. However, the WHO does not state which evidence or score they used to assess the different risk profiles per region nor how they validated the score in each country. The WHO also acknowledges that there are limitations with these risk scores, such as which risk factors are most predictive of events and whether new risk factors (eg, waist-hip ratio) should be included. They add that there is strong evidence that reducing the level of these risk factors has beneficial effects, which is probably the main take-home message for general practitioners from both Asian and Western countries.

\section{Guidelines in Asian versus Western countries}

Disease management guidelines recommend the use of aspirin for the prevention of first and recurrent CVD events in high-risk patients (usually defined as having a 10-year CHD 
Table 2 Summary of recommendations for aspirin use from a selection of recent European and US guidelines

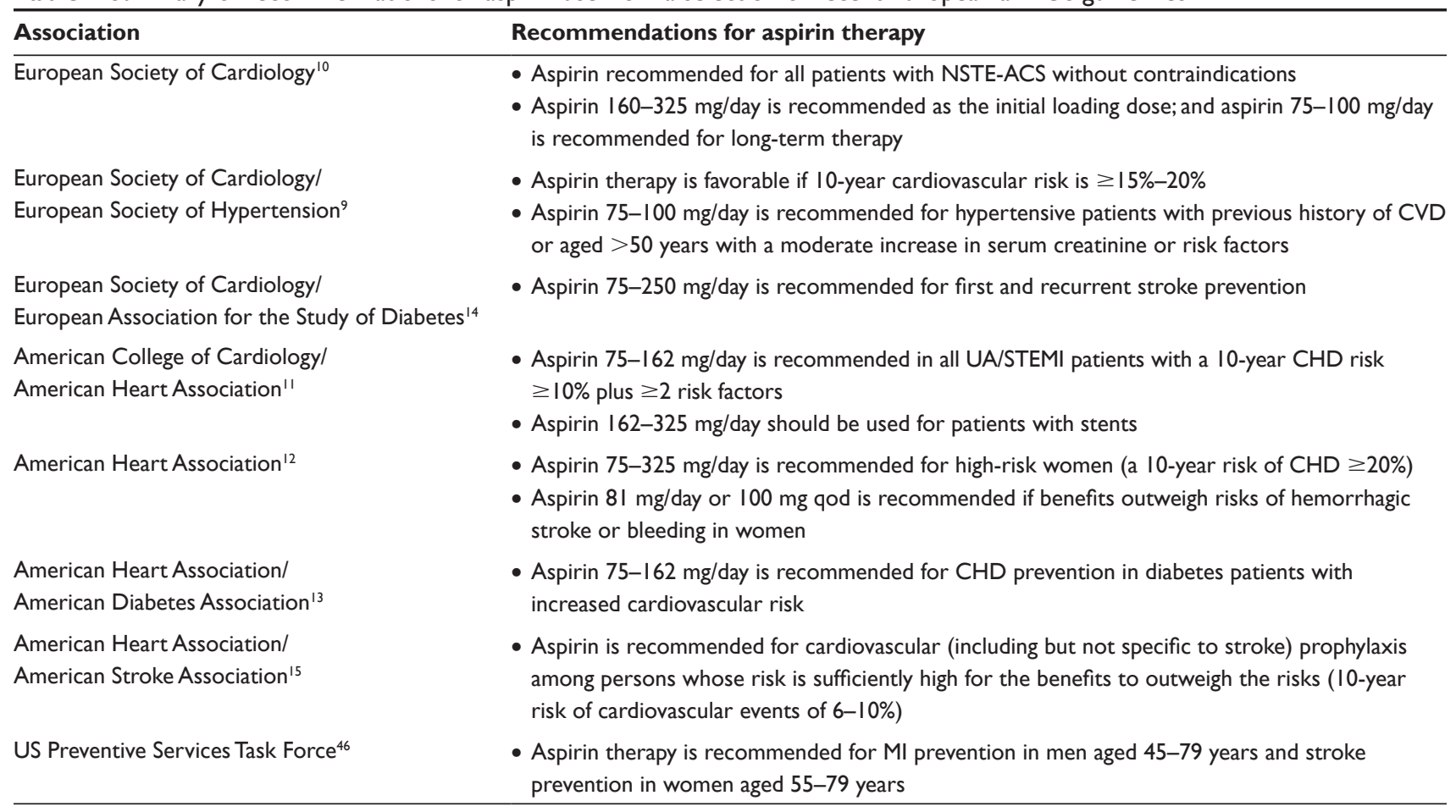

Abbreviations: CHD, coronary heart disease; CVD, cardiovascular disease; MI, myocardial infarction; NSTE-ACS, non-ST-segment elevation acute coronary syndrome; UA/STEMI, unstable angina/non-ST-elevation myocardial infarction; qod, once daily.

risk of $20 \%-30 \%$ according to the Framingham model). Table 2 summarizes recommendations from the main European and US guidelines..$^{9-15,46}$ In addition, the Chinese guidelines recommend prophylaxis in patients with a 10 -year CHD $\geq 10 \%$ as predicted by the Framingham model. ${ }^{47}$ The recently published US Preventive Services Task Force (USPSTF) guidelines recommend aspirin prophylaxis when the number of CVD events prevented (MI in men and stroke in women) outweighs any potential side effects such as gastrointestinal (GI) bleeds (Figure 3) ${ }^{46}$ In order to determine the threshold for treatment, the guidelines recommend a CHD risk estimation tool for men and a stroke estimation tool for women; however, the guidelines do not discuss how these scores have been validated in both Western and Asian populations.

Yoon et $\mathrm{a}^{48}$ found that application of the NCEP-ATP III guidelines, which were mainly developed from Caucasian patients, to data from the Korea Acute Myocardial Infarction Registry (KAMIR) resulted in undertreatment. Around 69\% of patients with an acute MI did not qualify for drug therapy when they were stratified according to the risk factors present and the 10-year CHD risk. Again, this indicates that risk estimation scores specific to Asian populations are warranted, particularly to determine the risk:benefit threshold of aspirin use in each ethnic group. Important differences between populations should be considered when extrapolating guidelines developed in one country for use in another. ${ }^{39}$ Underutilization of prophylactic agents is a key issue in Asian countries, which may, in part, be due to an overestimation of bleeding risks. ${ }^{49}$ It is possible that a lack of validated risk estimation models and guidelines in these countries could be a contributing factor to poor utilization rates.

\section{Clinical efficacy of aspirin in CVD prevention} First event reduction

Much of the evidence supporting the role of aspirin in the prevention of first CVD events comes from several largescale trials, which are summarized in Table $3.50-56$

A meta-analysis of five of these key trials (Physicians' Health Study [PHS], British Male Doctors' Trial [BDT], Hypertension Optimal Trial [HOT], Thrombosis Prevention Project [TPP], and the Primary Prevention Project [PPP]) reported a $32 \%$ reduction in the risk of a first MI and a $15 \%$ reduction in any important vascular events (combined endpoint of vascular death, nonfatal MI, or nonfatal stroke) associated with aspirin use. ${ }^{57} \mathrm{~A}$ further meta-analysis that also incorpo- 


\begin{tabular}{|c|c|c|c|}
\hline \multicolumn{2}{|c|}{$\begin{array}{c}\text { Men } \\
\text { age } 45-79 \text { years }\end{array}$} & \multicolumn{2}{|c|}{$\begin{array}{c}\text { Women } \\
\text { age } 55-79 \text { years }\end{array}$} \\
\hline \multicolumn{2}{|c|}{$\begin{array}{c}\text { Encourage aspirin use } \\
\text { when potential CVD benefit } \\
\text { (MIs prevented) } \\
\text { outweighs potential harm } \\
\text { of GI hemorrhage }\end{array}$} & \multicolumn{2}{|c|}{$\begin{array}{c}\text { Encourage aspirin use } \\
\text { when potential CVD benefit } \\
\text { (strokes prevented) } \\
\text { outweighs potential harm } \\
\text { of Gl hemorrhage }\end{array}$} \\
\hline \multirow{2}{*}{\multicolumn{2}{|c|}{$\begin{array}{r}\text { Risk leve } \\
\text { events pre } \\
\text { excee }\end{array}$}} & $\begin{array}{l}\text { hich CVD } \\
\text { d (benefit) } \\
\text { harms }\end{array}$ & \\
\hline & & \multicolumn{2}{|r|}{ 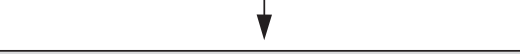 } \\
\hline \multicolumn{2}{|r|}{ Men } & \multicolumn{2}{|r|}{ Women } \\
\hline Age & 10-year CHD risk & Age & 10-year stroke risk \\
\hline 45-59 years & $\geq 4 \%$ & $55-59$ years & $\geq 3 \%$ \\
\hline 60-69 years & $\geq 9 \%$ & 60-69 years & $\geq 8 \%$ \\
\hline 70-79 years & $\geq 12 \%$ & 70-79 years & $\geq 11 \%$ \\
\hline
\end{tabular}

Figure 3 Summary of recommendations for low-dose aspirin therapy from the US Preventive Services Task Force. ${ }^{46}$

Abbreviations: CHD, coronary heart disease; CVD, cardiovascular disease; GI, gastrointestinal; MI, myocardial infarction.

rated data from the Women's Health Study (WHS) ${ }^{53}$ showed that aspirin significantly reduces the combined risk of CHD, nonfatal MI, and cardiovascular events. ${ }^{58}$ The most recent meta-analysis performed by the Antithrombotic Trialists' Collaboration (ATTC), which also included all six primary prevention trials $(n=95,000)$, showed that aspirin was associated with a $12 \%$ reduction in serious vascular events. ${ }^{59}$

The Japanese Primary prevention of atherosclerosis with Aspirin for Diabetes (JPAD) trial, ${ }^{56}$ which is not included in the meta-analyses to date, has provided important data on the role of low-dose aspirin ( $80-100 \mathrm{mg} /$ day) in the prevention of first cardiovascular events in 2539 Japanese subjects with Type 2 diabetes. After a follow-up period of around four years, aspirin therapy was associated with a trend toward a $20 \%$ reduction in atherosclerotic events, including fatal or nonfatal CHD, fatal or nonfatal stroke, transient ischemic attack, and peripheral arterial disease. JPAD also showed a significant reduction in vascular death in patients with diabetes who received low-dose aspirin. In a subgroup analysis, aspirin was associated with a significant reduction in atherosclerotic events in patients aged $\geq 65$ years. Since the overall event rates were lower than expected, it is possible that a greater benefit

Table 3 An overview of aspirin trials for the prevention of primary events

\begin{tabular}{|c|c|c|c|c|c|c|c|}
\hline & PHS $^{50}$ & $\mathrm{BDT}^{51}$ & HOT $^{52}$ & WHS $^{53}$ & $\mathbf{P P P}^{54}$ & TPT $^{55}$ & JPAD $^{56}$ \\
\hline Main country & US & UK & 26 countries & US & Italy & UK & Japan \\
\hline Aspirin dose & $325 \mathrm{mg}$ qod & $500 \mathrm{mg} /$ day & $75 \mathrm{mg} /$ day & 100 mg qod & 100 mg/day & $75 \mathrm{mg} /$ day & $8 \mathrm{I}-100 \mathrm{mg} /$ day \\
\hline Patients (n) & 22,071 & 5139 & 18,790 & 39,876 & 4495 & 5499 & 2539 \\
\hline $\begin{array}{l}\text { Reduction in } \\
\mathrm{CV} \text { events (\%) }\end{array}$ & 44 (MI) & 10 (mortality) & $\begin{array}{l}15 \text { (major CV } \\
\text { events) }\end{array}$ & I7 (stroke) & $\begin{array}{l}23 \text { (composite } \\
\mathrm{CV} \text { endpoint) }\end{array}$ & $20(\mathrm{IHD})$ & $\begin{array}{l}20 \\
32 \text { ( } \geq 65 \text { years) }\end{array}$ \\
\hline Conclusions & $\begin{array}{l}\text { Aspirin reduces } \\
\text { MI }\end{array}$ & $\begin{array}{l}\text { No significant } \\
\text { difference between } \\
\text { aspirin or placebo }\end{array}$ & $\begin{array}{l}\text { Aspirin reduces } \\
\text { major } C V \text { events }\end{array}$ & $\begin{array}{l}\text { Aspirin reduces } \\
\text { stroke (no effect } \\
\text { on MI or CV death) }\end{array}$ & Terminated early & $\begin{array}{l}\text { Aspirin reduces } \\
\text { nonfatal IHD }\end{array}$ & $\begin{array}{l}\text { Aspirin beneficial } \\
\text { in older patients }\end{array}$ \\
\hline
\end{tabular}

Abbreviations: PHS, Physicians' Health Study; BDT, British Male Doctors' Trial; HOT, Hypertension Optimal Trial; WHS, Women's Health Study; PPP, Primary Prevention Project; TPT, Thrombosis Prevention Trial; JPAD, Japanese Primary Prevention of Atherosclerosis with Aspirin for Diabetes; CV, cardiovascular; IHD, ischemic heart disease; qod, once daily. 
of aspirin therapy could have been observed in a larger trial population with a longer duration of follow-up..$^{60}$

The JPAD trial also demonstrates the safety of low-dose aspirin in a Japanese population, with the risk of hemorrhagic stroke, which is the most serious potential complication of aspirin therapy, being no greater among patients receiving aspirin than in the control group (six versus seven, respectively). ${ }^{56}$ This observation is of particular clinical importance given that hemorrhagic stroke is more common in Japanese than Western populations, and it demonstrates the tolerability of low-dose aspirin therapy in this high-risk Japanese population. ${ }^{60}$

Overall, the JPAD study confirms the role of aspirin in the prevention of first events in an Asian population. ${ }^{56}$ However, to date, there are no trials that have directly compared the efficacy of aspirin in the prevention of first events according to ethnicity.

\section{Recurrent event reduction}

The ATTC clearly demonstrated the benefits of low-dose aspirin (75-150 mg/day) for the prevention of recurrent events in trials involving 17,000 patients. ${ }^{8}$ In patients with a prior history of vascular disease, antiplatelet therapy, of which aspirin was the most widely studied, was associated with notable reductions of approximately $25 \%$ in the risk of a combined outcome of any serious vascular event, $32 \%$ in the risk of nonfatal MI, 25\% in the risk of nonfatal stroke, and $15 \%$ in the risk of vascular mortality. The most recent metaanalysis from the same group, ${ }^{59}$ which analyzed data from 16 secondary prevention trials in 17,000 patients, showed that aspirin was associated with a greater reduction in serious adverse events compared with placebo $(6.7 \%$ versus $8.2 \%$ per year, $P<0.0001)$.

Data from Asia are similarly conclusive, in that use of aspirin $50 \mathrm{mg}$ /day in Chinese patients $(\mathrm{n}=216)$ has been associated with a reduction of $65 \%$ in the incidence of secondary reinfarction compared with patients who received no antiplatelet therapy. ${ }^{61}$ It is interesting to note that in this study, the reduction in incidence of secondary reinfarction was observed in males, but no significant trend was observed in females. In addition, the Japanese Antiplatelets Myocardial Infarction Study (JAMIS) demonstrated that long-term low-dose aspirin $(81 \mathrm{mg} /$ day $)$ prevented recurrent acute MI in postinfarction patients after thrombolysis or coronary angioplasty. ${ }^{62}$ Finally, the Chinese Acute Stroke Trial (CAST, $n=21,106$ ) confirmed the benefits of aspirin treatment (160 mg/day) started within 48 hours of a suspected acute ischemic stroke. ${ }^{63}$ In patients treated with aspirin for up to four weeks, there was a significant reduction in the combined in-hospital endpoint of death or nonfatal stroke compared with untreated patients $(12 \%$ proportional risk reduction, $P=0.03)$.

In summary, the findings from these trials indicate that aspirin is effective in the prevention of recurrent events in both European and Asian cohorts. There are no studies that have directly compared the effect of aspirin on the prevention of recurrent events according to race; however, the findings from the ATTC indicate that recurrent MI was reduced by $32 \%$ compared with $65 \%$ in the Chinese study. ${ }^{8,59}$ Although it is difficult to make comparisons given the huge difference in patient numbers, and differences related to other factors such as treatment duration, definition of endpoints, time since first MI, age, sex and other characteristics, it is possible that ethnicity may also be a contributory factor.

\section{Combination therapy in high-risk patients} Multidrug regimens including aspirin are often recommended as a comprehensive CVD preventive strategy. ${ }^{14}$ Furthermore, combined therapy with more than one antiplatelet agent may offer improved cardiovascular protection owing to the additive effects of activating complementary antiplatelet pathways. However, combining aspirin with another antiplatelet agent should take into account benefits gained over safety issues. For example, the Clopidogrel for High Atherothrombotic Risk and Ischemic Stabilization, Management, and Avoidance (CHARISMA) and Management of Atherothrombosis with Clopidogrel in High-risk Patients (MATCH) trials showed that the combination of clopidogrel plus aspirin was comparable with aspirin alone in high-risk populations, but the risk of bleeding was higher with combination therapy (Table 4). ${ }^{64-71}$

A recent meta-analysis of five trials has also demonstrated that aspirin plus pravastatin was more effective than either agent alone in the prevention of recurrent events, including ischemic stroke. ${ }^{72}$ The Aspirin and Simvastatin Combination for Cardiovascular Events Prevention Trial in Diabetes (ACCEPT-D) is currently investigating the effects of adding low-dose aspirin $100 \mathrm{mg}$ /day to existing simvastatin therapy on the prevention of cardiovascular events in 5170 patients with Type 1 and Type 2 diabetes, an area in which data are surprisingly scarce. ${ }^{73}$ This study will provide important new information on the role of aspirin in diabetes when used in addition to other CVD prevention strategies. The ongoing A Study of Cardiovascular Events iN Diabetes (ASCEND) trial, which is evaluating the effect of aspirin with or without omega-3 fatty acids on CVD events in patients with diabetes over a five-year follow-up 


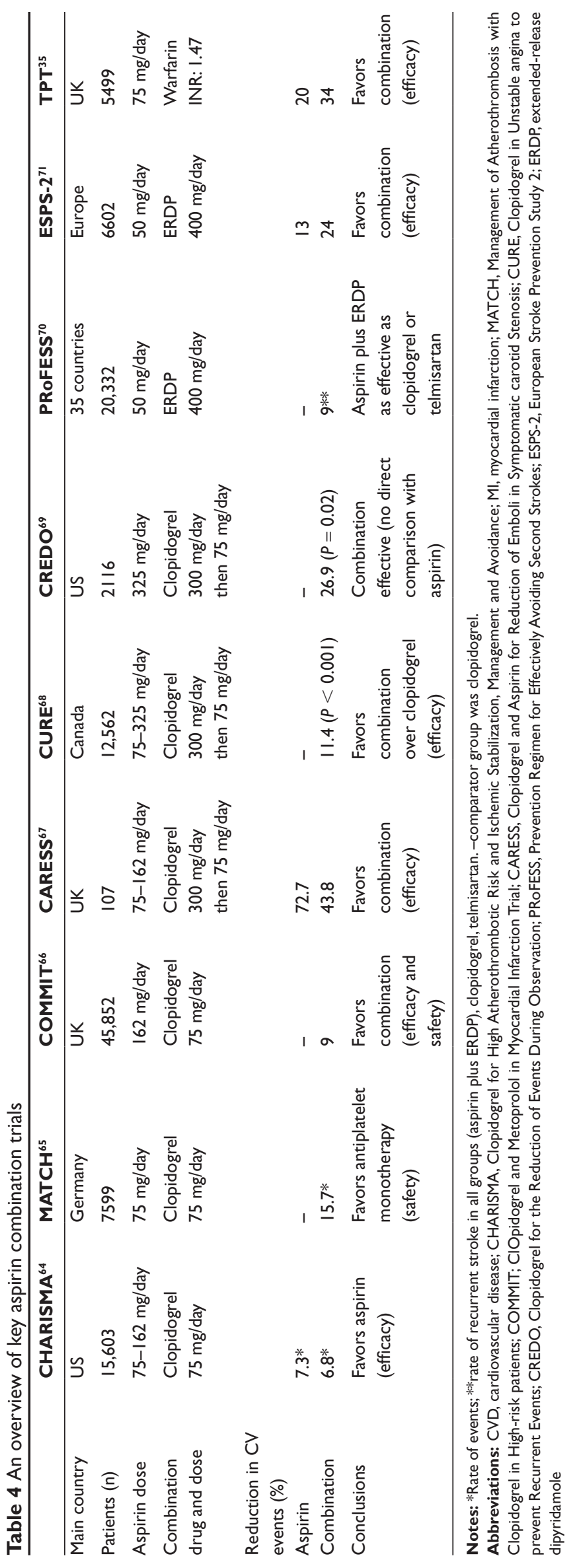


period, will also provide additional information on aspirin in high-risk patients (Table 5). ${ }^{74}$

In addition, the triple combination of aspirin, clopidogrel, and enoxaparin is associated with a reduction in mortality and reinfarctions compared with standard therapy of unfractionated heparin in patients with ACS. ${ }^{75}$ Multiple regimens involving aspirin have been shown to be effective on a global scale. A research group recently estimated that a preventive regimen for high-risk patients based on aspirin, a statin, and two antihypertensives could help avert 17.9 million CVD deaths over 10 years (estimates based on 23 low- to middleincome countries). ${ }^{76}$

\section{Aspirin safety}

The most common side effect associated with aspirin is bleeding, which is related to its mechanism of action and the dose prescribed. ${ }^{77}$ The risk of GI hemorrhage with long-term use of aspirin was assessed in a meta-analysis of 24 randomized controlled trials involving almost 66,000 participants taking aspirin or no aspirin over a one-year treatment period. ${ }^{78}$ This analysis showed that GI hemorrhage was slightly higher in patients taking aspirin compared with no aspirin/placebo (2.47\% versus $1.42 \%$, respectively; OR: $1.68 ; 95 \%$ CI: $1.51-1.88)$. The risk of GI hemorrhage was reduced when lower aspirin doses ( $<163 \mathrm{mg} /$ day $)$ were used $(2.30 \%$ versus 1.45\% (OR: 1.59 ; 95\% CI: $1.40-1.81$ ).

The impact of aspirin on hemorrhagic stroke has been addressed in another meta-analysis of 16 trials involving more than 55,000 participants. ${ }^{79}$ The mean dose of aspirin was $273 \mathrm{mg} /$ day and the mean duration of treatment was 37 months. There was an increased absolute risk of 12 events $(95 \%$ CI: 5-20) per 10,000 persons over approximately three years, or about 0.4 excess events per 1000 users annually $(P<0.001)$ associated with aspirin use. However, in this analysis, aspirin use was also associated with an absolute risk reduction in MI of 137 events per 10,000 persons $(P<0.001)$ and an absolute risk reduction in ischemic stroke of 39 events per 10,000 persons $(P<0.001)$. Overall, there was a clear benefit in the population at risk. In another meta-analysis involving almost 57,000 subjects from 16 trials, there was no difference between aspirin and placebo in the risk of noncardiovascular death (RR: 0.92; 95\% CI: $0.81-1.04) .{ }^{80}$ It may be useful to re-examine the patients enrolled in these three key safety meta-analyses to determine how many were from Asian communities and to provide the risk factors for these patients alone.

In addition to the risks described above, the likelihood of adverse effects associated with aspirin also depends on the patient's inherent risk level, so risk assessments should take into account any underlying conditions that predispose the patient to bleeding, such as hemophilia, uremia, or previous peptic ulcer. ${ }^{81}$ Again, it is important to note that different populations may have different inherent risks that will affect the patient's threshold for prophylaxis. Physician concerns about safety issues could also have an impact on utilization of prophylactic agents. A recent Taiwanese study in patients with atrial fibrillation $(n=39,541)$ showed

Table 5 Ongoing studies with aspirin

\begin{tabular}{|c|c|c|c|}
\hline Trial name & Country & $\begin{array}{l}\text { Cardiovascular risk } \\
\text { factors in patients }\end{array}$ & Intervention \\
\hline $\begin{array}{l}\text { Diabetic Atherosclerosis Prevention } \\
\text { by Cilostazol (DAPC) study }\end{array}$ & $\begin{array}{l}\text { Japan, China, Philippines, } \\
\text { and Korea }\end{array}$ & Diabetic atherosclerosis & $\begin{array}{l}\text { Cilostazol and } \\
\text { aspirin }\end{array}$ \\
\hline $\begin{array}{l}\text { Japanese Primary Prevention } \\
\text { Project with Aspirin (JPPP) }\end{array}$ & Japan & $\begin{array}{l}\text { At least one of: hypertension, } \\
\text { hyperlipidemia, diabetes }\end{array}$ & $\begin{array}{l}\text { Enteric-coated } \\
\text { aspirin } 100 \mathrm{mg}\end{array}$ \\
\hline $\begin{array}{l}\text { Low Dose Aspirin and Statins } \\
\text { for Primary Prevention of } \\
\text { Atherosclerosis and Arterial } \\
\text { Thromboembolism in Systemic } \\
\text { Lupus Erythematosus (SLE) }\end{array}$ & Hong Kong & $\begin{array}{l}\text { Atherosclerosis, } \\
\text { thromboembolism, SLE }\end{array}$ & $\begin{array}{l}\text { Aspirin } 80 \mathrm{mg}, \\
\text { rosuvastatin } 10 \mathrm{mg}\end{array}$ \\
\hline $\begin{array}{l}\text { Aspirin Dose and Atherosclerosis } \\
\text { in Patients with Metabolic } \\
\text { Syndrome (PAD) }\end{array}$ & US & Metabolic syndrome & $\begin{array}{l}\text { Aspirin } 81,162 \text {, } \\
325,650 \text {, or } 1300 \mathrm{mg}\end{array}$ \\
\hline $\begin{array}{l}\text { A Study to Assess the Efficacy } \\
\text { and Safety of } 100 \text { mg Acetylsalicylic } \\
\text { Acid in Patients at Moderate Risk } \\
\text { of Cardiovascular Disease (ARRIVE) }\end{array}$ & US, Italy, Puerto Rico & $\begin{array}{l}\text { At least two of: hypertension, } \\
\text { hypercholesterolemia, diabetes, } \\
\text { smoker, family history of early } \\
\text { coronary heart disease }\end{array}$ & $\begin{array}{l}\text { Enteric-coated } \\
\text { aspirin } 100 \mathrm{mg}\end{array}$ \\
\hline $\begin{array}{l}\text { ASCEND:A Study of Cardiovascular } \\
\text { Events in Diabetes }\end{array}$ & UK & Diabetes mellitus & $\begin{array}{l}\text { Aspirin, } \\
\text { omega-3-acid supplements }\end{array}$ \\
\hline
\end{tabular}


that only $24.7 \%$ of the population received antithrombotic therapy. The main reason for low prescription rates was concern over bleeding risks. ${ }^{49}$ Overestimation of bleeding risk in Asian countries is an issue that needs to be addressed in guidelines with risk:benefit ratios that are tailored to these countries.

However, to date, there are no direct safety comparisons of aspirin in European versus Asian cohorts. This is a key area where further research is warranted because risk factors for GI ulceration may vary between the two regions; for example, Helicobacter pylori may be higher in Asian than European populations. ${ }^{82}$ Although the industrialization of Asian countries could erode this difference, it is possible that some Asian patients may be more susceptible to GI ulceration and may need lower doses of aspirin or concomitant use of gastroprotective agents. There is also evidence to suggest that the pattern of $H$. pylori infection may differ between Korean and Japanese patients compared with Americans. ${ }^{83}$ The incidence of GI bleeding may also be affected by genetic differences related to cytochrome polymorphisms, which is another reason why comparative studies are needed. These factors may be a reason why aspirin is underutilised in Asian countries. $^{49,21}$

\section{Minimizing adverse events by low-dose aspirin}

The risk of GI bleeding appears to be linked to aspirin dose and can be minimized by using a low-dose strategy; for example, use of aspirin $75 \mathrm{mg} /$ day is estimated to reduce the risk of GI bleeding by $40 \%$ compared with $300 \mathrm{mg} /$ day, and by $30 \%$ compared with $150 \mathrm{mg} /$ day. $^{78}$ Improved formulations, such as enteric-coated aspirin, can also reduce the risk of GI bleeding. ${ }^{84}$ The antithrombotic efficacy of aspirin does not appear to be dose-dependent. Therefore, physicians should be encouraged to prescribe the lowest dose possible to ensure protection from cardiovascular events. Many guidelines support the use of low doses for primary prevention (as summarized in Table 2); however, in practice, prescription of higher doses is common. In a systematic review of published clinical trials, aspirin at doses as high as $1300 \mathrm{mg}$ /day are approved for use; however, much lower doses (75-81 mg/day) have been shown to be as effective as higher doses with a lower risk of dose-related side effects such as GI bleeding. ${ }^{85}$ Another survey of 7363 physicians showed that there were significant differences in the prescribing patterns between European and Asian countries. $^{20,21}$ In Europe, $82 \%$ of physicians prescribed aspirin $100 \mathrm{mg} /$ day for post-MI patients compared with
$63 \%$ in Asia $(P<0.00001)$. There was a tendency for Asian countries to prescribe a wider range of aspirin doses.

\section{Variable response to aspirin}

Variations in individual responses to aspirin have been observed in clinical practice, which has led to the concept that certain individuals are resistant to some of its effects. ${ }^{86}$ There is currently no universally accepted definition of "variable response", although it has been described as the failure of aspirin therapy to produce expected biologic effects, such as the inhibition of platelet aggregation, inhibition of thromboxane biosynthesis, or the failure to prevent atherosclerotic thrombosis in some patients. No diagnostic test of platelet function is currently recommended to assess the effects of aspirin in individual patients. Furthermore, incidence rates vary widely among studies, from $0.4 \%$ to $83 \%,{ }^{87-90}$ which may reflect methodological differences in quantifying resistance rather than true resistance. Thus current opinion suggests that rather than being a medical phenomenon, variable response is actually the combined result of patient noncompliance when taking low-dose aspirin, possible drug-drug interactions, and lack of appropriate methods of cyclooxygenase-1 measurement. ${ }^{91}$

\section{The future for aspirin in Asia}

The large and growing number of deaths attributable to CVD clearly suggests a need for prevention, and more studies are warranted in Asian communities together with greater exploration of risk estimation scores and tailored guidelines. A number of studies are currently ongoing that should hopefully address some of the data needs (Table 5). The Japanese Primary Prevention Project (JPPP) is currently underway to evaluate the balance of risks and benefits of low-dose, enteric-coated aspirin in elderly Japanese patients (60-85 years) with one or more cardiovascular risk factors (hypertension, hyperlipidemia, and/or diabetes). The study is designed to recruit 10,000 subjects who will be randomized to receive either aspirin $100 \mathrm{mg} /$ day or placebo. A composite of nonfatal MI and/or stroke and cardiovascular death will be evaluated in the trial, and results are expected in $2010 .^{92}$ In addition, the Diabetic Atherosclerosis Prevention by Cilostazol (DAPC) study, a collaboration between researchers from Japan, China, Philippines, and Korea, is investigating the efficacy of aspirin and cilostazol in the prevention and treatment of diabetic atherosclerosis in Asian patients $(n=408)$. The intima media thickness of the carotid artery will be assessed as the primary endpoint, with secondary endpoints 
Table 6 Recommendations and concerns regarding aspirin use in Asian and Western populations

- Aspirin is underutilized in high-risk patients in both Asian and Western countries, which indicates a need for educational initiatives and improved physician-patient communication across all countries

- Risk estimation scores are useful guides for determining the threshold at which aspirin should be used; however, greater validation is needed in countries such as Japan, India and in South Asia. Until validated scores are available, physicians should be aware of the limitations and should monitor risk factors that are relevant to their patient but are not covered in all scores (eg, triglyceride levels in Japanese patients or high density lipoprotein cholesterol in South Asians)

- Large-scale trials addressing the benefits of aspirin in preventing recurrent events in Asian populations are needed; the prevention of recurrent myocardial infarction may be higher in Chinese patients

- Underutilization of aspirin in Asian countries may be linked to an overestimation of bleeding risks. It is possible that a higher prevalence of Helicobacter pylori infection and genetic differences may make Asian populations more susceptible to gastrointestinal bleeding. Until further trials are available, very low aspirin doses and even the wide use of gastroprotective agents may be the optimal approach to high-risk patients in Asian countries

including incidence of cardiovascular events and all-cause mortality. ${ }^{93}$

Further studies are also needed to identify the true prevalence of aspirin-associated adverse events in Asian populations, and to determine the risk:benefit ratio according to underlying CVD risk levels. In CAST, despite a trend toward more hemorrhagic strokes in patients treated with aspirin compared with placebo $(P>0.1)$, the increased risk of adverse events did not influence the conclusion that the benefits of aspirin treatment for hospitalized stroke patients far outweighed the risks. ${ }^{63}$ Therefore, additional evidence is needed from specific populations at defined risks that can form the basis for relevant local guidelines. There is also a growing trend toward using aspirin in combination with other agents, including herbs such as ginkgo biloba, in Asian countries. ${ }^{94}$ Studies are needed to assess the possible benefits of such an approach.

\section{Summary}

Based on the current evidence and the recommendations from US and European guidelines, aspirin should be used for CVD prevention for all clinical conditions in which its risk: benefit ratio is favorable. Long-term, low-dose aspirin therapy is currently recommended for the prevention of severe vascular events in moderate- and high-risk patients (including diabetics) and those with a history of vascular events. These guidelines should be followed to ensure optimal prevention of cardiovascular events, with the knowledge that risk estimation scores may need to be validated in a wider range of Asian countries in order to identify more accurate risk: benefit thresholds. A number of trials are already underway, including the DAPC and JPPP in Asia, which will provide key data on the benefits of aspirin in Asian patients at risk of CVD. The recommendations and concerns regarding aspirin use are summarized in Table 6.

\section{Acknowledgment}

Editorial assistance was funded by Bayer Schering Pharma.

\section{Disclosure}

The authors declare no conflicts of interest in this work.

\section{References}

1. Gaziano JM. Global burden of cardiovascular disease. In: Libby P, Bonow RO, Mann DL, et al. editors. Libby: Braunwald's Heart Disease: A Textbook of Cardiovascular Medicine. 8th ed. Philadelphia, PA: Saunders; 2007:1-21.

2. American Heart Association 2004. International Cardiovascular Disease Statistics. Available from: http://www.americanheart.org/presenter jhtml?identifier=3001008. Accessed September 14, 2009.

3. World Health Organization 2004. Atlas of Heart Disease and Stroke. Available from: http://www.who.int/cardiovascular_diseases/resources/ atlas/en/index.html. Accessed September 14, 2009.

4. The George Institute. China program fact sheet. Available from www. thegeorgeinstitute.org/library/b30064_3.pdf. Accessed September 14, 2009.

5. Murray CJ, Lopez AD. Alternative projections of mortality and disability by cause 1990-2020: Global Burden of Disease Study. Lancet 1997;349(9064):1498-1504.

6. Leeder S, Raymond S, Greenberg M, et al. A Race Against Time: The Challenge of Cardiovascular Disease in Developing Economies. New York, NY: Columbia University, 2004.

7. Abegunde DO, Mathers CD, Adam T, Ortegon M, Strong K. The burden and costs of chronic diseases in low-income and middle-income countries. Lancet. 2007;370(9603):1929-1938.

8. Antithrombotic Trialists' Collaboration. Collaborative meta-analysis of randomised trials of antiplatelet therapy for prevention of death myocardial infarction, and stroke in high risk patients. BMJ. 2002;324(7329):71-86.

9. Mancia G, De BG, Dominiczak A, et al. Guidelines for the Management of Arterial Hypertension: The Task Force for the Management of Arterial Hypertension of the European Society of Hypertension (ESH) and of the European Society of Cardiology (ESC). J Hypertens. 2007;25(6):1105-1187.

10. Bassand JP, Hamm CW, Ardissino D, et al. Guidelines for the diagnosis and treatment of non-ST-segment elevation acute coronary syndromes. Eur Heart J. 2007;28(13):1598-1660.

11. Anderson JL, Adams CD, Antman EM, et al. ACC/AHA 2007 guidelines for the management of patients with unstable angina/non-ST-Elevation myocardial infarction: A report of the American College of Cardiology/ American Heart Association Task Force on Practice Guidelines (Writing Committee to Revise the 2002 Guidelines for the Management of Patients With Unstable Angina/Non-ST-Elevation Myocardial Infarction) developed in collaboration with the American College of Emergency Physicians, the Society for Cardiovascular Angiography and Interventions, and the Society of Thoracic Surgeons endorsed by the American Association of Cardiovascular and Pulmonary Rehabilitation and the Society for Academic Emergency Medicine. J Am Coll Cardiol. 2007;50(7):e1-e157. 
12. Mosca L, Banka CL, Benjamin EJ, et al. Evidence-based guidelines for cardiovascular disease prevention in women: 2007 update. Circulation. 2007;115(11):1481-1501.

13. Buse JB, Ginsberg HN, Bakris GL, et al. Primary prevention of cardiovascular diseases in people with diabetes mellitus: A scientific statement from the American Heart Association and the American Diabetes Association. Diabetes Care. 2007;30(1):162-172.

14. Ryden L, Standl E, Bartnik M, et al. Guidelines on diabetes, pre-diabetes, and cardiovascular diseases: Executive summary. The Task Force on Diabetes and Cardiovascular Diseases of the European Society of Cardiology (ESC) and of the European Association for the Study of Diabetes (EASD). Eur Heart J. 2007;28(1):88-136.

15. Goldstein LB, Adams R, Alberts MJ, et al. Primary prevention of ischemic stroke: A guideline from the American Heart Association/ American Stroke Association Stroke Council: cosponsored by the Atherosclerotic Peripheral Vascular Disease Interdisciplinary Working Group; Cardiovascular Nursing Council; Clinical Cardiology Council; Nutrition, Physical Activity, and Metabolism Council; and the Quality of Care and Outcomes Research Interdisciplinary Working Group: The American Academy of Neurology affirms the value of this guideline. Stroke. 2006;37(6):1583-1633.

16. Stafford RS, Monti V, Ma J. Underutilization of aspirin persists in US ambulatory care for secondary and primary prevention of cardiovascular disease. PLoS Med. 2005;2(12):e353.

17. Pignone M, Anderson GK, Binns K, Tilson HH, Weisman SM. Aspirin use among adults aged 40 and older in the United States: Results of a national survey. Am J Prev Med. 2007;32(5):403-407.

18. Khalil MZ, Abba AA. Management of acute myocardial infarction. Do we follow guidelines applied in practice? Saudi Med J. 2003;24:1234-1237.

19. Bi Y, Gao R, Patel A, et al. Evidence-based medication use among Chinese patients with acute coronary syndromes at the time of hospital discharge and 1 year after hoapitalization: Results from the Clinical Pathways for Acute Coronary Syndromes in China (CPACS) study. Am Heart J. 2009; 157:509-516.

20. Zaninelli A, Kaufholz C, Schwappach D. Physicians' attitudes toward post-MI aspirin prophylaxis: Findings from an online questionnaire in Europe and Latin-America. Postgrad Med. 2009;121:44-53.

21. Zaninelli A, Hu DY, Kaufholz C, Schwappach D. Physicians' attitudes toward post-MI aspirin prophylaxis: Findings from an online questionnaire in Asia-Pacific. Postgrad Med. 2010;122(1):108-117.

22. Song XT, Chen YD, Pan WQ, Lü SZ. CRACE investigators. Gender based differences in patients with acute coronary syndrome: Findings from Chinese Registry of Acute Coronary Events (CRACE). Chin Med $J$ (Engl). 2007;120(12):1063-1067.

23. Yamazaki T, Goto S, Shigematsu H, et al. Prevalence, awareness and treatment of cardiovascular risk factors in patients at high risk of atherothrombosis in Japan. Circ J. 2007;71(7):995-1003.

24. Gaziano JM, Manson JE, Ridker PM. Primary and secondary prevention of coronary heart disease. In: Libby P, Bonow RO, Mann DL, et al. editors. Libby: Braunwald's Heart Disease: A Textbook of Cardiovascular Medicine. 8th ed. Philadelphia, PA: Saunders; 2007; 1119-48.

25. Gaziano TA, Young CR, Fitzmaurice G, Atwood S, Gaziano JM. Laboratory-based versus non-laboratory-based method for assessment of cardiovascular disease risk: The NHANES I follow-up study cohort. Lancet. 2008;371(9616):923-31.

26. World Health Organization. Prevention of Cardiovascular Disease. Guidelines for assessment and management of cardiovascular risk. 2007. Available from: www.who.int > ... > Cardiovascular disease > Guidelines. Accessed on March 17, 2010.

27. Third Report of the National Cholesterol Education Program (NCEP) Expert Panel on Detection, Evaluation, and Treatment of High Blood Cholesterol in Adults (Adult Treatment Panel III) final report. Circulation. 2002;106:3143-3421.

28. Conroy RM, Pyorala K, Fitzgerald AP, et al. Estimation of ten-year risk of fatal cardiovascular disease in Europe: The SCORE project. Eur Heart J. 2003;24:987-1003.
29. Assmann G, Cullen P, Schulte H. Simple scoring scheme for calculating the risk of acute coronary events based on the 10-year follow-up of the prospective cardiovascular Munster (PROCAM) study. Circulation. 2002;105:310-315.

30. New Zealand Guidelines Group guidelines. Available at: http://www. nzgg.org.nz. Accessed January 15, 2010.

31. Ridker PM, Paynter NP, Rifai N, Gaziano JM, Cook NR. C-reactive protein and parental history improve global cardiovascular risk prediction: The Reynolds Risk Score for men. Circulation. 2008;118:2243-2251.

32. Ridker PM, Buring JE, Rifai N, Cook NR. Development and validation of improved algorithms for the assessment of global cardiovascular risk in women: the Reynolds Risk Score. JAMA. 2007;297:611-619.

33. Hippisley-Cox J, Coupland C, Vinogradova Y, Robson J, May M, Brindle P. Derivation and validation of QRISK, a new cardiovascular disease risk score for the United Kingdom: Prospective open cohort study. BMJ. 2007;335:136.

34. Wilson PWF, D'Agostino RB, Levy D, Belanger AM, Silbershatz H, Kannel WB. Prediction of coronary heart disease using risk factor categories. Circulation. 1998;97(18):1837-1847.

35. Framingham model. Available at : http://cvrisk.mvm.ed.ac.uk/calculator/ calc.asp?framingham. Accessed January 15, 2010.

36. Liu J, Hong Y, D'Agostino RB Sr, et al. Predictive value for the Chinese population of the Framingham CHD risk assessment tool compared with the Chinese Multi-Provincial Cohort Study. JAMA. 2004;291(21):2591-2599.

37. Wu YF, Liu XQ, Li X, et al. Estimation of 10-year risk of fatal and nonfatal ischemic cardiovascular diseases in Chinese adults. Circulation. 2006;114(21):2217-2225

38. Gu D, Gupta A, Muntner P, et al. Prevalence of cardiovascular disease risk factor clustering among the adult population of China: Results from the International Collaborative Study of Cardiovascular Disease in Asia (InterAsia). Circulation. 2005;112(5):658-665.

39. Morimoto T, Fukui T, Lee TH, Matsui K. Application of US guidelines in other countries: Aspirin for the primary prevention of cardiovascular events in Japan. Am J Med. 2004;117(7):459-468.

40. Joshi P, Islam S, Reddy S, et al. Risk factors for early myocardial infarction in South Asians compared with individuals in other countries. JAMA. 2007;297:286-294.

41. Karthikeyan G, Teo KK, Islam S, et al. Lipid profile, plasma apolipoproteins, and risk of a first myocardial infarction among Asians: An analysis from the INTERHEART Study. $\mathrm{J}$ Am Coll Cardiol. 2009;53:244-253.

42. Enas EA, Yusuf S, Mehta J. Prevalence of coronary artery disease in Asian Indians. Am J Cardiol. 1992;70:945-949.

43. McKeigue PM, Marmot MG. Mortality from coronary heart disease in Asian communities in London. BMJ. 1988;297(6653):903.

44. Balarajan R. Ethnic differences in mortality from ischaemic heart disease and cerebrovascular disease in England and Wales. $B M J$. 1991;302:560-564.

45. Kuller LH. Ethnic differences in atherosclerosis, cardiovascular disease and lipid metabolism. Curr Opin Lipidol. 2004;15:109-113.

46. US Preventive Services Task Force. Aspirin for the prevention of cardiovascular disease: US Preventive Services Task Force Recommendation Statement. Ann Intern Med. 2009;150(6):396-404.

47. Chinese Society of Cardiology Chinese Medical Association. Editorial Board of Chinese Journal of Cardiology. The clinical use of aspirin in patients with atherosclerotic cardiovascular disease: 2005 Chinese Expert Consensus Document. Chin J Cardiol. 2006;34:281-284.

48. Yoon YE, Rivera JJ, Kwon DA, et al. National Cholesterol Education Panel III guidelines performance role in preventing myocardial infarction in a large cohort without a history of coronary artery disease: Korea Acute Myocardial Infarction Registry study. Prev Cardiol. 2009;12(2):109-113.

49. Lin LJ, Cheng MH, Lee CH, Wung DC, Cheng CL, Kao Yang YH. Compliance with antithrombotic prescribing guidelines for patients with atrial fibrillation - a nationwide descriptive study in Taiwan. Clin Ther. 2008;30(9):1726-1736. 
50. Steering Committee of the Physicians' Health Study Research Group. Final report on the aspirin component of the ongoing Physicians' Health Study. N Engl J Med. 1989;321(3):129-135.

51. Peto R, Gray R, Collins R, et al. Randomised trial of prophylactic daily aspirin in British male doctors. BMJ. 1988;296(6618):313-316.

52. Hansson L, Zanchetti A, Carruthers SG, et al. Effects of intensive blood-pressure lowering and low-dose aspirin in patients with hypertension: Principal results of the Hypertension Optimal Treatment (HOT) randomized trial. Lancet. 1998;351(9118):1755-1762.

53. Ridker PM, Cook NR, Lee IM, et al. A randomized trial of low-dose aspirin in the primary prevention of cardiovascular disease in women. N Engl J Med. 2005;352(13):1293-1304.

54. Sacco M, Pellegrini F, Roncaglioni MC, et al. Primary prevention of cardiovascular events with low-dose aspirin and vitamin E in type 2 diabetic patients: Results of the Primary Prevention Project (PPP) trial. Diabetes Care. 2003;26(12):3264-3272.

55. The Medical Research Council's General Practice Research Framework. Thrombosis prevention trial: Randomized trial of low-intensity oral anticoagulation with warfarin and low-dose aspirin in the primary prevention of ischaemic heart disease in men at increased risk. Lancet. 1998;351(9098):233-241.

56. Ogawa H, Nakayama M, Morimoto T, et al. Low-dose aspirin for primary prevention of atherosclerotic events in patients with type 2 diabetes: A randomized controlled trial. JAMA. 2008;300(18):2134-2141.

57. Eidelman RS, Hebert PR, Weisman SM, Hennekens CH: An update on aspirin in the primary prevention of cardiovascular disease. Arch Intern Med. 2003;163(17):2006-2010.

58. Bartolucci AA, Howard G. Meta-analysis of data from the six primary prevention trials of cardiovascular events using aspirin. Am J Cardiol. 2006;98(6):746-750.

59. Antithrombotic Trialists' (ATT) Collaboration. Aspirin in the primary and secondary prevention of vascular disease: Collaborative metaanalysis of individual participant data from randomized trials. Lancet. 2009;373(9678):1849-1860.

60. Nicolucci A. Aspirin for primary prevention of cardiovascular events in diabetes: Still an open question. JAMA. 2008;300(18): 2180-2181.

61. Chen Z, Xu Y, Yu Q, et al. Secondary prevention of myocardial reinfarction with low dose aspirin. Chin Med Sci J. 1991;6(3): 141-144.

62. Yasue H, Ogawa H, Tanaka H, et al. Effects of aspirin and trapidil on cardiovascular events after acute myocardial infarction. Japanese Antiplatelets Myocardial Infarction Study (JAMIS) Investigators. Am J Cardiol. 1999;83(9):1308-1313.

63. CAST Collaborative Group. CAST: randomised placebo-controlled trial of early aspirin use in 20,000 patients with acute ischaemic stroke. CAST (Chinese Acute Stroke Trial) Collaborative Group. Lancet. 1997;349(9066):1641-1649.

64. Bhatt DL, Fox KA, Hacke W, et al. Clopidogrel and aspirin versus aspirin alone for the prevention of atherothrombotic events. $N$ Engl J Med. 2006;354(16):1706-1717.

65. Diener HC, Bogousslavsky J, Brass LM, et al. Aspirin and clopidogrel compared with clopidogrel alone after recent ischaemic stroke or transient ischaemic attack in high-risk patients (MATCH): Randomized, double-blind, placebo-controlled trial. Lancet. 2004;364(9431): 331-337.

66. Chen ZM, Jiang LX, Chen YP, et al. Addition of clopidogrel to aspirin in 45,852 patients with acute myocardial infarction: Randomized placebo-controlled trial. Lancet. 2005;366(9497):1607-1621.

67. Markus HS, Droste DW, Kaps M, et al. Dual antiplatelet therapy with clopidogrel and aspirin in symptomatic carotid stenosis evaluated using Doppler embolic signal detection: The Clopidogrel and Aspirin for Reduction of Emboli in Symptomatic Carotid Stenosis (CARESS) trial. Circulation. 2005;111(17):2233-2240

68. Yusuf S, Zhao F, Mehta SR, et al. Effects of clopidogrel in addition to aspirin in patients with acute coronary syndromes without ST-segment elevation. $N$ Engl J Med. 2001;345(7):494-502.
69. Steinhubl SR, Berger PB, Mann JT 3rd, et al. Early and sustained dual oral antiplatelet therapy following percutaneous coronary intervention: A randomized controlled trial. JAMA. 2002;288(19):2411-2420.

70. Diener HC, Sacco RL, Yusuf S, et al. Effects of aspirin plus extended-release dipyridamole versus clopidogrel and telmisartan on disability and cognitive function after recurrent stroke in patients with ischemic stroke in the Prevention Regimen for Effectively Avoiding Second Strokes (PRoFESS) trial: A double-blind, active and placebocontrolled study. Lancet Neurol. 2008;7(10):875-884.

71. Diener HC, Cunha L, Forbes C, Sivenius J, Smets P, Lowenthal A. European Stroke Prevention Study 2: Dipyridamole and acetylsalicylic acid in secondary prevention of stroke. J Neurol Sci. 1996;143(1-2):1-13.

72. Hennekens CH, Sacks FM, Tonkin A, et al. Additive benefits of pravastatin and aspirin to decrease risks of cardiovascular disease. Randomized and observational comparisons of secondary prevention trials and their meta-analyses. Arch Intern Med. 2004;164(1):40-44.

73. De Berardis G, Sacco M, Evangelista V, et al. Aspirin and Simvastatin Combination for Cardiovascular Events Prevention Trial in Diabetes (ACCEPT-D): Design of a randomized study of the efficacy of lowdose aspirin in the prevention of cardiovascular events in subjects with diabetes mellitus treated with statins. Trials. 2007;8:21.

74. A Study of Cardiovascular Events iN Diabetes: Available from: http:// www.clinicaltrials.gov/ct2/show/NCT00135226?term=ASCEND+asp irin\&rank=1. Accessed September 14, 2009.

75. Heer T, Juenger C, Gitt AK, et al. Efficacy and safety of optimized antithrombotic therapy with aspirin, clopidogrel and enoxaparin in patients with non-ST segment elevation acute coronary syndromes in clinical practice. J Thromb Thrombolysis. 2008;28(3):325-332.

76. Lim SS, Gaziano TA, Gakidou E, et al. Prevention of cardiovascular disease in high-risk individuals in low-income and middle-income countries: Health effects and costs. Lancet. 2007;370(9604):2054-2062.

77. Patrono C, Coller B, Dalen JE, et al. Platelet-active drugs: The relationships among dose, effectiveness, and side effects. Chest. 2001;119 (1 Suppl):S39-S63.

78. Derry S, Loke YK. Risk of gastrointestinal haemorrhage with long term use of aspirin: Meta-analysis. BMJ. 2000;321(7270):1183-1187.

79. He J, Whelton PK, Vu B, Klag MJ. Aspirin and risk of hemorrhagic stroke: A meta-analysis of randomized controlled trials. JAMA. 1998;280(22):1930-1935.

80. McQuaid K, Laine L. Systematic review and meta-analysis of adverse events of low-dose aspirin and clopidogrel in randomized controlled trials. Am J Med. 2006;119(8):624-638.

81. Patrono C, Coller B, FitzGerald GA, Hirsh J, Roth G. Platelet-active drugs: The relationships among dose, effectiveness, and side effects: The seventh ACCP conference on antithrombotic and thrombolytic therapy. Chest. 2004;126(S Suppl):S234-S264.

82. Leong RW. Differences in peptic ulcer between the East and the West. Gastroenterol Clin N Am. 2009;38:363-379.

83. Lee I, Lee H, Kim M, et al. Ethnic difference of Helicobacter pylori gastritis: Korean and Japanese gastritis is characterized by male- and antrum-predominant acute foveolitis in comparison with American gastritis. World J Gastroenterol. 2005;11:94-98.

84. Cole AT, Hudson N, Liew LC, Murray FE, Hawkey CJ, Heptinstall S. Protection of human gastric mucosa against aspirin-enteric coating or dose reduction? Aliment Pharmacol Ther. 1999;13(2):187-193.

85. Campbell CL, Smyth S, Montalescot G, Steinhubl SR. Aspirin dose for the prevention of cardiovascular disease: A systematic review. JAMA. 2007;297(18):2018-2024

86. Papathanasiou A, Goudevenos J, Tselepis AD. Aspirin resistance in cardiovascular disease: Pathogenesis, diagnosis and clinical impact. Curr Pharm Des. 2009;15:1085-1094.

87. Wang CB, Hu DY, Shi XB, Zhu ZY, Zhu JY, Yang JG. Aspirin resistance in patients taking small dose of aspirin. Zhongguo Wei Zhong Bing Ji Jiu Yi Xue. 2006;18(4):219-223. Chinese.

88. Chen WH, Cheng X, Lee PY, et al. Aspirin resistance and adverse clinical events in patients with coronary artery disease. Am J Med. 2007;120(7):631-635. 
89. Lee PY, Chen WH, Ng W, et al. Low-dose aspirin increases aspirin resistance in patients with coronary artery disease. $\mathrm{Am} \mathrm{J} \mathrm{Med.}$ 2005;118(7):723-727.

90. Lordkipanidze M, Pharand C, Palisaitis DA, Diodati JG. Aspirin resistance: Truth or dare. Pharmacol Ther. 2006;112(3):733-743.

91. Patrono C, Rocca B. Drug insight: Aspirin resistance - fact or fashion? Nat Clin Pract Cardiovasc Med. 2007;4(1):42-50.

92. Japanese Primary Prevention Project with aspirin: Available from: http:// www.clinicaltrials.gov/ct2/show/NCT00225849?term=JPPP\&rank=1. Accessed September 14, 2009.
93. Yamasaki Y, Kim YS, Kawamori R. Rationale and protocol of a trial for prevention of diabetic atherosclerosis by using antiplatelet drugs: Study of Diabetic Atherosclerosis Prevention by Cilostazol (DAPC study). Cardiovasc Diabetol. 2006;5:16.

94. Chang LC, Huang N, Chou YJ, Kao FY, Hsieh PC, Huang YT. Patterns of combined prescriptions of aspirin-Ginkgo biloba in Taiwan: A population-based study. J Clin Pharm Ther. 2008;33(3):243-249.

\section{Publish your work in this journal}

Vascular Health and Risk Management is an international, peerreviewed journal of therapeutics and risk management, focusing on concise rapid reporting of clinical studies on the processes involved in the maintenance of vascular health; the monitoring, prevention and treatment of vascular disease and its sequelae; and the involvement of metabolic disorders, particularly diabetes. This journal is indexed on PubMed Central and MedLine. The manuscript management system is completely online and includes a very quick and fair peer-review system, which is all easy to use. Visit http://www.dovepress.com/ testimonials.php to read real quotes from published authors.

Submit your manuscript here: http://www.dovepress.com/vascular-health-and-risk-management-journal 